Armand Puig i Tàrrech

\title{
Jesus: An Uncommon Journey
}

\author{
Studies on the Historical Jesus
}

[Jesus. Eine ungewöhnliche Reise. Studien zum historischen Jesus.]

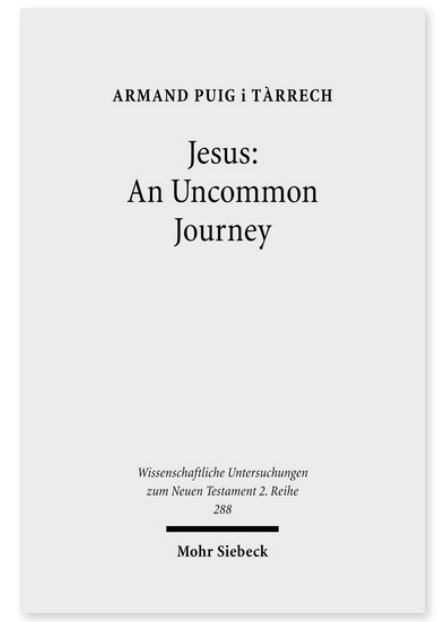

2010. XII, 310 Seiten. WUNT II 288

ISBN 978-3-16-151631-3

DOI 10.1628/978-3-16-151631-3

eBook PDF $94,00 €$

ISBN 978-3-16-150504-1

fadengeheftete Broschur 94,00€
Veröffentlicht auf Englisch.

Die Annäherung an den historischen Jesus ist eine faszinierende Aufgabe, die zahlreiche interpretative Möglichkeiten offen hält. Eine allgemeine Ansicht ist schwer zu finden, und sowohl methodologische Einsicht als auch wissenschaftlicher

Austausch sind dazu nötig. Wie die vielfältigen neutestamentlichen Schriften zeigen, scheint es fast unmöglich, die Figur des Rabbis von Nazareth, seine Tätigkeit und Identität wirklich zu verstehen. Somit kann das Leben Jesu als eine Reise gesehen werden, die unübliche Entwicklungen und eine bestimmte Perspektive widerspiegelt: die Beziehung zwischen ihm und Gott, dem Vater. Armand Puig i Tàrrech scheut keine schwierigen Themen wie Jesu Geburt und Familie, die normalerweise nicht im third quest behandelt werden. Zudem findet der Leser weitere Schlüsselfragen, die für die historische Jesusforschung von Bedeutung sind: die Taufe; die Frage, ob er ein Mystiker war und die Traditionen, die er initiierte.

Armand Puig i Tàrrech Born 1953; 1984 PhD in Biblical Sciences; 1993 Coordinator of the Catalan Ecumenical Bible (BCI); 1997 Co-Director of the »Corpus Biblicum Catalanicum«; 1999 Ordinarius for New Testament in the Theological Faculty of Catalonia (Barcelona); 2006 President-Dean of the Faculty; 2009 Deputy-President elect of the »Studiorum Novi Testamenti Societas« (SNTS).

\section{Jetzt bestellen:}

https://mohrsiebeck.com/buch/jesus-an-uncommon-journey-9783161516313?no_cache=1

order@mohrsiebeck.com

Telefon: +49 (0)7071-923-17

Telefax: $+49(0) 7071-51104$ 